\title{
Cardiac and vascular complications in rheumatoid arthritis
}

\author{
Prashanth Rawla \\ Department of Medicine, SOVAH Health, Martinsville, Virginia, United States
}

\begin{abstract}
Rheumatoid arthritis (RA) is an independent risk factor for the development of a variety of cardiovascular diseases, with a 1.5-factor increase in risk. This literature review aims to provide a global overview of the pathogenesis, effects of anti-rheumatoid treatment on cardiovascular risk, a description of the cardiovascular complications associated with RA, and current opinion on cardiovascular risk assessment and management in patients with RA.

Author conducted a literature search in PubMed, Scopus, Web of Science and Embase regarding RA and associated cardiovascular complications. The mechanism of increased risk of cardiovascular disease in patients with RA is complex. There are specific genetic factors associated with both diseases, and traditional cardiovascular risk factors may be more prevalent in patients with RA. Most anti-rheumatic drugs decrease cardiovascular risk, and general recommendations focus on reduction of disease activity and strict management of cardiovascular risk as per the general population.
\end{abstract}

Key words: inflammation, atherosclerosis, rheumatoid arthritis, cardiovascular.

\section{Introduction}

It is widely recognized that patients with rheumatoid arthritis (RA) are at an increased risk of cardiovascular (CV) related morbidity and mortality compared to the general population. This increased risk is independent of traditional risk factors such as age, smoking, gender, hypertension, and hyperlipidemia. There is a general consensus that a 1.5 multiplication factor is used when using unadapted cardiovascular disease (CVD) predictor algorithms in patients with RA [1].

There is an increased understanding of the pathogenesis of CV disease in RA, and it appears to be related to shared inflammatory and immune mediators. Furthermore, the management of RA involves a plethora of drugs that can directly or indirectly affect CV risk. Non-steroidal anti-inflammatory drugs (NSAIDs) for example, are associated with increased risk, but on the other hand tumor necrosis factor (TNF) inhibitors and methotrexate are associated with a decreased risk [2].

This review aims to summarize current knowledge relating to CV diseases in patients with RA, from the pathogenesis and epidemiological aspect.

\section{Methods}

Author searched PubMed, Scopus, Web of Science and Embase in September 2018 using the terms "cardiovascular disease" or "cardiovascular event" or "cardiovascular system" or "cardiovascular risk," and "rheumatoid arthritis." The most recent relevant reviews, systematic reviews, or meta-analysis were used for the synthesis of this article, together with any more recent relevant articles that added further knowledge to the topic.

\section{Pathogenesis of cardiovascular risk factors in rheumatoid arthritis}

The increased risk of cardiovascular events in patients with RA is multifactorial. The traditional risk factors such as smoking, hypertension, and hyperlipidemia are of course still important, and the presence of RA exerts an additional independent risk. There is already evidence of a complex interplay of factors not yet fully understood. Figure 1 shows the various mechanisms causing endothelial dysfunction and vascular damage leading to CVD in RA. Table I shows an overview of the risk factors involved in CVD in RA patients. 


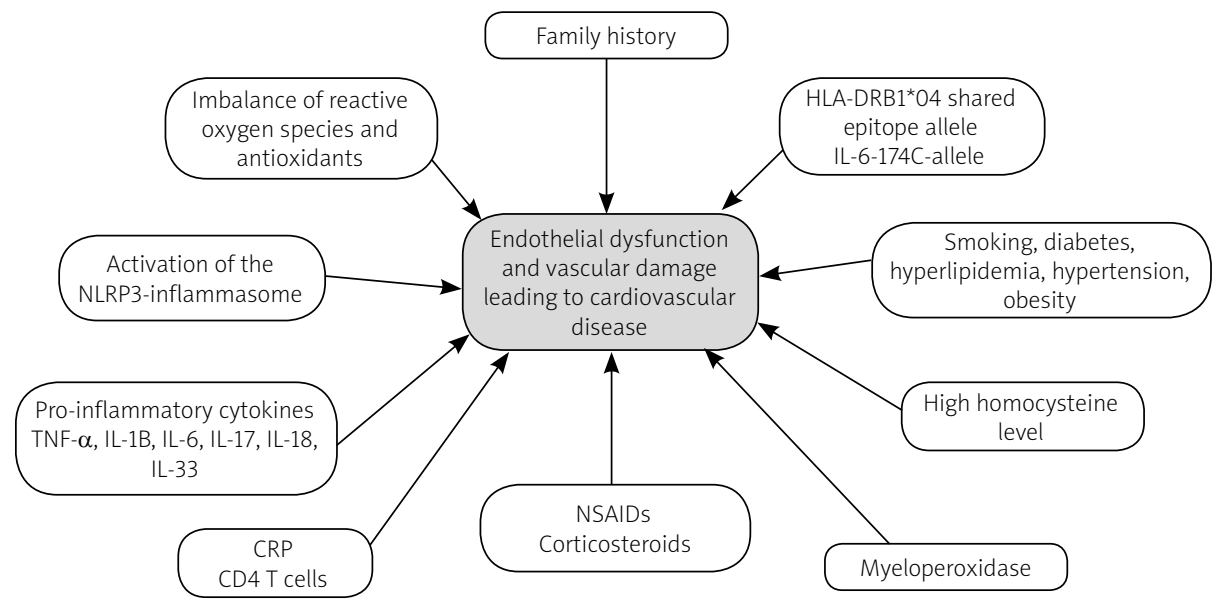

Fig. 1. Various mechanisms causing endothelial dysfunction and vascular damage leading to cardiovascular disease in rheumatoid arthritis.

\section{Inflammation}

Rheumatoid arthritis and some cardiovascular conditions are recognized as chronic inflammatory conditions. In the pre-clinical stages of RA, there is decreased self-tolerance of the immune system with production of autoantibodies, followed by activation of the immune system, and infiltration of the synovial joints by immune cells at the clinical/symptomatic phase. The process is quite complex with a plethora of cytokines involved, including various TNF and interleukins (IL). It appears that the pro-inflammatory cytokines, TNF, IL-1B, and IL-6, play a central role in the pathogenesis of RA. Similarly, cytokines are also involved in the pathogenesis of atherosclerosis. The role of IL- 6 in atherosclerosis is still controversial. However, it is one of the most abundant cytokines found in atherosclerotic plaques, and there is an indication that both TNF- $\alpha$ and IL- 6 are pro-atherogenic [3]. Other similarities in the pathogenesis of RA and atherosclerosis include the activation of the NLRP3-inflammasome as a potential contributor to the inflammatory process in both diseases [4].

\section{Endothelial dysfunction}

Part of the pathogenesis of atherosclerosis is endothelial activation. Normally, endothelium responds to physical and chemical signals in order to maintain vascular homeostasis by the production of a variety of factors. These factors control muscle tone, cell adhesion and proliferation, thrombo-resistance, and local inflammation, allowing the endothelium to participate in the inflammatory response [5]. In the situation where there is prolonged activation via pathologic stimuli, such as due to smoking, hypertension, chronic systemic infections, and chronic in- flammation, there is a high risk of endothelial dysfunction with up-regulation of cellular adhesion molecules, changes in muscle tone and wall permeability to substances such as lipoproteins, ultimately leading to accumulation of macrophages and fibrous tissue. Plaque formation ensues with the potential of rupturing and causing thrombosis and other cardiovascular events. Rheumatoid arthritis, being a chronic inflammatory condition, is also associated with endothelial dysfunction, and hence it is independently linked to the pathogenesis of atherosclerosis. However, endothelial function does not appear to be dependent on rheumatoid disease activity [6].

\section{Oxidative stress}

This is another potentially shared pathogenesis for RA and CVD. Imbalance of reactive oxygen species and antioxidants in patients with RA has been linked to myocardial strain, impairment of the function of high-density lipoproteins, and also to endothelial dysfunction [7]. This is an indication of the complexity surrounding the various factors at play linking cardiovascular disease and rheumatoid arthritis.

\section{Family history and genetic factors}

Although a family history of premature cardiovascular events has been shown to be more prevalent in some patients with RA, other studies have not shown the same clinical association [8]. Similarly, there is conflicting evidence about how a family history of CVD influences the CVD risk in patients with RA compared to those without RA. Some studies indicate there is no influence, and others report that parental history of fatal CVD has an additional effect beyond the already increased risk [8]. 
Table I. Overview of risk factors involved in cardiovascular disease in rheumatoid arthritis patients

\begin{tabular}{|c|c|c|}
\hline \multicolumn{2}{|r|}{ Risk factors } & Factors to consider in rheumatoid arthritis patients \\
\hline \multirow{7}{*}{  } & $\begin{array}{l}\text { Age and } \\
\text { gender }\end{array}$ & $\begin{array}{l}\text { Male gender and older age were independently associated with the occurrence of CV events; other factors } \\
\text { independently associated with CVD risk include hypertension, hyperlipidemia, and ever smoking }\end{array}$ \\
\hline & Hypertension & $\begin{array}{l}\text { Hypertension is an independent predictor of CVD events; inflammation, physical inactivity, and medications impact } \\
\text { blood pressure in RA patients } \\
\text { Drugs used for the treatment of RA such as NSAIDs and glucocorticoids (GCS) are associated with increased risk } \\
\text { for hypertension } \\
\text { A } 20 \mathrm{~mm} \mathrm{Hg} \text { increase in systolic blood pressure is associated with significant CVD events }\end{array}$ \\
\hline & Dyslipidemia & $\begin{array}{l}\text { The mechanism by which lipids affect CVD in RA patient is multifactorial and complex } \\
\text { Presence of active inflammation decreases total cholesterol (TC) levels } \\
\text { In patients with active RA low total cholesterol and low-density lipoprotein cholesterol levels are seen, but the rate } \\
\text { of having a myocardial infarction is } 1.6 \text { times higher than patients without RA } \\
\text { High C-reactive protein is associated with increased CVD risk } \\
\text { DMARDs, TNF- } \alpha \text { inhibitors, tocilizumab and IL-6 receptor blocker cause a significant increase in lipid levels }\end{array}$ \\
\hline & $\begin{array}{l}\text { Insulin } \\
\text { resistance/ } \\
\text { metabolic } \\
\text { syndrome }\end{array}$ & $\begin{array}{l}\text { Metabolic syndrome increases the risk of CVD two-fold compared to the general population; prevalence of meta- } \\
\text { bolic syndrome in RA patients is around 30-40\%; an essential factor for the development of CVD risk in metabolic } \\
\text { syndrome is insulin resistance; glucocorticoids, which are commonly used to treat RA-related symptoms, promote } \\
\text { insulin resistance }\end{array}$ \\
\hline & Obesity & $\begin{array}{l}\text { Obesity is independently associated with CVD as well as other CVD risk factors such as hypertension, dyslipidemia, } \\
\text { insulin resistance; obesity is associated with endothelial dysfunction and promotion of atherosclerosis }\end{array}$ \\
\hline & $\begin{array}{l}\text { Physical } \\
\text { activity }\end{array}$ & $\begin{array}{l}\text { Physical inactivity is associated with higher risk of myocardial infarction } \\
\text { Several studies indicate that patients with RA are frequently inactive; patients with RA have low cardiopulmonary } \\
\text { fitness, which is associated with CVD and all-cause mortality }\end{array}$ \\
\hline & Smoking & $\begin{array}{l}\text { RA patients who smoke have aggressive disease and worse clinical outcomes; smoking has an additive effect on } \\
\text { the risk of stroke; studies have shown an increased risk of CVD events in smokers compared to non-smoker } \\
\text { RA patients }\end{array}$ \\
\hline \multirow{4}{*}{ 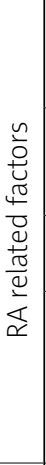 } & Inflammation & $\begin{array}{l}\text { Pro-inflammatory cytokines, TNF, IL-1B, and IL-6, play a central role in the pathogenesis of RA; similarly, cytokines are } \\
\text { also involved in the pathogenesis of atherosclerosis } \\
\text { Activation of the NLRP3-inflammasome is also a potential contributor to the inflammatory process and CVD }\end{array}$ \\
\hline & $\begin{array}{l}\text { Endothelial } \\
\text { dysfunction }\end{array}$ & $\begin{array}{l}\text { Endothelial activation plays a part in the pathogenesis of atherosclerosis; rheumatoid arthritis, being a chronic } \\
\text { inflammatory condition, is associated with endothelial dysfunction and hence it is independently linked to the } \\
\text { pathogenesis of atherosclerosis }\end{array}$ \\
\hline & $\begin{array}{l}\text { Oxidative } \\
\text { stress }\end{array}$ & $\begin{array}{l}\text { Imbalance of antioxidants and reactive oxygen species in patients with RA has been linked to myocardial strain, } \\
\text { impairment of the function of high-density lipoproteins, and also to endothelial dysfunction }\end{array}$ \\
\hline & $\begin{array}{l}\text { Family } \\
\text { history } \\
\text { and genetic } \\
\text { factors }\end{array}$ & $\begin{array}{l}\text { Although a family history of premature cardiovascular events has been shown to be more prevalent in some } \\
\text { patients with RA, other studies have not shown the same clinical association } \\
\text { Human leukocyte antigen and related genes (HLA-DRB1*04 shared epitope allele), TNF superfamily genes (TNF- } \alpha \\
\text { and TNF- } \beta \text { cytokines) are implicated in vascular inflammation; presence of above specific alleles in patients with } \\
\text { RA has been shown to increase CV risk }\end{array}$ \\
\hline \multirow{6}{*}{ 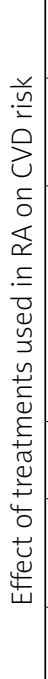 } & NSAIDs & $\begin{array}{l}\text { NSAIDs have been associated with increased CVD risk in the general population; NSAIDs, especially rofecoxib, } \\
\text { increases the risk of CVD events in RA; the role of other NSAIDs and CVD risk in RA patients is controversial }\end{array}$ \\
\hline & Steroids & $\begin{array}{l}\text { Glucocorticoids are associated with insulin resistance, hypertension, hyperlipidemia, obesity, and DM, all of which } \\
\text { are associated with the development of CVD; they increase CV risk in a dose-dependent fashion; however, some } \\
\text { studies suggest that GCS may prove beneficial in reducing CVD risk by controlling inflammation }\end{array}$ \\
\hline & DMARDs & $\begin{array}{l}\text { Methotrexate: seems to reduce CV risk in RA by its effects on cholesterol and free radicals, as well as by blocking } \\
\text { the effects of pro-atherosclerotic cytokines such as IL-11, IL-6, and TNF- } \alpha \\
\text { Sulfasalazine: potentially reduces CV morbidity in patients with rheumatoid arthritis by inhibition of platelet } \\
\text { function } \\
\text { Hydroxychloroquine: is associated with a better metabolic profile and reduced incidence of CVD morbidity } \\
\text { Leflunomide and cyclosporin: are associated with hypertension; cyclosporin protects against atherosclerosis; } \\
\text { the actual cardiovascular risk profile of these drugs is still uncertain }\end{array}$ \\
\hline & $\begin{array}{l}\text { TNF inhibi- } \\
\text { tors }\end{array}$ & $\begin{array}{l}\text { Inhibition of the action of TNFs results in a reduction of inflammation, and this should decrease the risk of CVD; } \\
\text { myocardial infarction risk is lower in patients receiving anti-TNF agents }\end{array}$ \\
\hline & $\begin{array}{l}\text { Non-TNF } \\
\text { biologics }\end{array}$ & $\begin{array}{l}\text { These drugs have a variety of mechanisms of actions which include anti-CD28 therapy (abatacept), anti-B-cell } \\
\text { therapy (rituximab), anti-IL- } 6 \text { (tocilizumab) and anti-IL-1 therapy (anakinra); a reduction in cardiovascular events } \\
\text { was observed when compared to patients who were either biologic-naive or had stopped the medication }\end{array}$ \\
\hline & Tofacitinib & $\begin{array}{l}\text { Although cholesterol levels were increased in patients taking this medication, the atherogenic index did not appear } \\
\text { to change }\end{array}$ \\
\hline
\end{tabular}


Nevertheless, a genetic link between these two conditions is demonstrated elsewhere. There are numerous studies examining specific polymorphisms, and it appears that, rather than a single gene being responsible, there are multiple and complex gene-to-gene and environmental interactions that result in this association. A notable example is the human leukocyte antigen (HLA) and related genes, which are the main genetic factors associated with inflammatory immune-mediated diseases, including RA. Patients with RA who carry two copies of a specific epitope allele, the HLA-DRB1*04 shared epitope allele, have a 2 -fold increase in mortality from ischemic heart disease [9].

Other genetic associations include the TNF superfamily genes, especially those that encode the TNF- $\alpha$ and TNF- $\beta$ cytokines. These have been proposed to be risk factors for the development of RA and are implicated in vascular inflammation. Presence of specific alleles in patients with RA have been shown to increase CV risk [10].

\section{Traditional risk factors - smoking, hypertension, diabetes, hyperlipidemia, obesity}

These factors are proven to be implicated in the pathogenesis of CVD in the general population. In patients with RA, smoking has an additive effect on the risk of stroke, and hypertension increases the risk of CVD even in young adults. Low-density lipoprotein cholesterol (LDL-C) does not have an association with coronary heart disease, and high-density lipoprotein cholesterol (HDL-C) is associated with a decreased risk for myocardial infarction and stroke in patients with RA [11]. Results from a meta-analysis indicate that cardiovascular morbidity increased with hypertension (relative risk [RR]: 2.24, 95\% confidence intervals [Cl]: 1.42-3.06), smoking (RR: 1.5, 95\% Cl: 1.15-1.84), obesity (RR: 1.16, 95\% Cl: 1.03-1.29), type 2 diabetes (RR: 1.94 , 95\% Cl: 1.58-2.30), and hypercholesterolemia (RR: 1.73, 95\% Cl: 1.03-2.44) in patients with RA [12].

In addition, patients with RA have a higher prevalence of metabolic syndrome (obesity, glucose intolerance, dyslipidemia, and hypertension). This further reinforces the consensus that the interaction between the various factors involved is very complex, and more than one pathway is involved in the increase in CVD risk in patients with RA.

\section{Effect of treatments used in rheumatoid arthritis on cardiovascular disease risk}

Management of RA is multifactorial, and it usually follows a step-wise approach depending on disease phase and response to treatment. Initial treatment focuses on symptom control with analgesics and physical therapy, and disease control with conventional disease-modifying antirheumatic drugs (CDMARD) as monotherapy. If the disease is not controlled, escalation is required with an increase in dosage with the potential addition of biologic or other drugs. The biologic drugs are so called because they are produced in live cell systems, and they are divided into those that inhibit TNF (anti-TNF) and those that inhibit some other cytokine, pathway or cell [13]. A new drug, tofacitinib, comprises a new type of pharmacological class called oral small-molecule inhibitors.

Each separate class of pharmacological agents influences cardiovascular risk in a different way. Some increase risk, such as NSAIDs, and others appear to reduce the risk to levels comparable to non-RA populations. Biologics have been associated with better CVD outcomes, and this is corroborated by findings where the progression of atherosclerosis reaches similar rates in patients with RA whose inflammation is managed well compared to those without RA [14].

\section{Non-steroidal anti-inflammatory drugs}

The association between non-steroidal anti-inflammatory drugs (NSAIDs) and cardiovascular risk has been known for many decades. A recent meta-analysis by Bally et al. [15] evaluated the acute myocardial infarction (AMI) risk for traditional and selective NSAIDs in the general population. The results indicate an increased risk from the first week of usage for all drugs, especially with high doses, and long-term use (> 30 days) did not carry additional risk, apart for diclofenac. It confirmed that rofecoxib was associated with the greatest risk (withdrawn from the market since 2004) and that celecoxib appeared to have a similar risk to traditional NSAIDs. A meta-analysis on patients with RA [2] did not find an increased risk for AMIs with the use of NSAIDs. However, there was an 18\% increased risk for any cardiac events, and the authors cautioned that there were not enough studies and the results should be interpreted with caution.

\section{Steroids}

Glucocorticosteroids are frequently given to patients with RA for acute exacerbations and also as a bridge treatment between changes in disease-modifying antirheumatic drugs (DMARDs). These have also been found to increase cardiovascular risk in patients with RA for all types of cardiac events, including AMI, even up to $47 \%$, and this association is also seen in other populations as well [16]. 
Based on various observational studies, even low doses of 5-10 mg of prednisolone per day carry additional risk. There also seems to be an association between steroids and any-cause mortality, which is dose dependent, with a threshold starting from $8 \mathrm{mg} / \mathrm{d}$ of prednisolone [17].

\section{Disease-modifying antirheumatic drugs}

The commonest and most important DMARD is methotrexate. Others include sulfasalazine, hydroxychloroquine, leflunomide, and cyclosporine. Methotrexate has demonstrated survival benefits over other DMARDs, and it seems to reduce cardiovascular risk in RA, based on results from a meta-analysis [2]. However, the exact mechanism behind this effect is not known. There are reports that it relates to its effects on cholesterol and free radicals, as well as by blocking the effects of pro-atherosclerotic cytokines such as IL-11, IL-6 and TNF- $\alpha$, resulting in improved endothelial function and vascular homeostasis. Animal studies have not confirmed a positive effect on endothelial function yet.

Sulfasalazine is advocated as monotherapy in patients who cannot receive methotrexate, and as combination therapy with methotrexate. Studies on patients with coronary heart disease and ankylosing spondylitis indicate a beneficial effect with regard to cardiovascular risk, and earlier reports indicate that it reduces cardiovascular morbidity in patients with rheumatoid arthritis $[18,19]$. A potential mechanism of action is the inhibition of platelet function [20].

Another drug is hydroxychloroquine, also used in combination with other DMARDs. It does not have the same benefit profile as other drugs. However, it seems to be associated with a better metabolic profile and reduced incidence of CVD morbidity [21, 22].

An association of leflunomide and cyclosporin with hypertension has been observed in some studies, although cyclosporin protects against atherosclerosis [23]. The actual cardiovascular risk profile of these drugs is still uncertain.

\section{Tumor necrosis factor inhibitors (anti-TNF)}

These biologics act either as receptors (etanercept) or antibodies against TNF (infliximab, adalimumab, certolizumab, golimumab). Inhibition of the action of TNF results in a reduction of inflammation, and this should decrease the risk of CVD. Current data support this hypothesis, as it has been found that myocardial infarction risk is lower in patients receiving anti-TNF agents compared to treatment-naive subjects (hazard ratio [HR]: $0.85,95 \% \mathrm{Cl}:$ 0.76-0.95), even compared to conventional DMARDs [24, 25].

\section{Non-TNF biologics}

These drugs have a variety of mechanism of actions which include anti-CD28 therapy (abatacept), anti-B-cell therapy (rituximab), anti-IL-6 (tocilizumab) and anti-IL-1 therapy (anakinra). Patients who are on such medication show a reduction in cardiovascular events compared to patients who are either biologic-naive or have stopped the medication (HR: 0.81, 95\% Cl: 0.70-0.95) [24].

There was a concern about tocilizumab because it increases serum lipid levels. However, it is also associated with a decreased cardiovascular risk, compared to other biologics $[26,27]$. Some authors believe that a contributing factor is an ability for this drug to regulate chemerin and adiponectin serum levels in patients with RA. These are classed as adipokines, mediators that are synthesized in adipose tissue and have been implicated in the pathophysiology of inflammation (with inconclusive results about RA), insulin resistance, and even atherogenesis [28].

\section{Tofacitinib}

Tofacitinib is the newest drug, a synthetic oral small molecule. Although in patients with RA who are given this drug, cholesterol levels increased, the atherogenic index did not appear to change. In a pooled analysis of multiple studies, the rate of CV events was found to be low, comparable to that of placebo and methotrexate [29]. Data from other populations also indicate a low incidence of major adverse CV events with tofacitinib [30].

\section{Cardiac and vascular complications of rheumatoid arthritis}

\section{Pericarditis}

Pericarditis is one of the most common cardiac manifestations in RA. Although the incidence of pericarditis in echocardiographic or post-mortem studies is high as $30-50 \%$, clinically it is seen in $<10 \%$ of patients with severe RA [31]. Pericarditis occurs most frequently in male patients with active rheumatoid disease and other extra-articular manifestations. There have been several reports associated with the development of acute and/or recurrent pericarditis in patients treated with anti-TNF agents [32]. Diagnosis is commonly by echocardiography. Treatment for mild disease is aspirin or NSAIDs and GCS for moderate to severe disease. Severe cases associated with cardiac tamponade, hemodynamically significant pericardial effusion, or constrictive pericarditis may require surgical management which may include pericardiocentesis, pericardiectomy, or pericardiotomy [33]. 


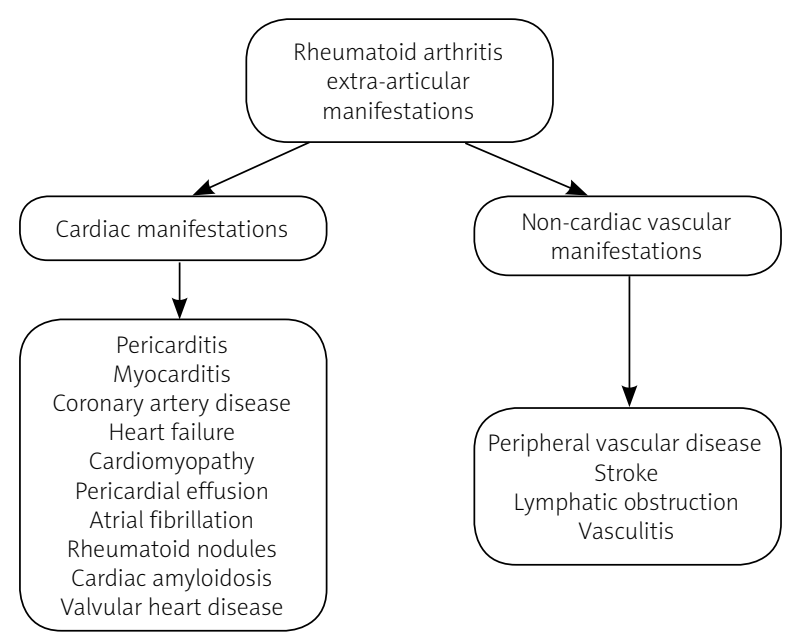

Fig. 2. Various cardiac and vascular complications of rheumatoid arthritis.

Figure 2 shows the various cardiac and vascular complications of RA.

\section{Myocarditis}

Myocarditis is rare in RA and is usually associated with active articular disease and other extra-articular manifestations of RA. The granulomatous form of myocarditis is more common in RA than the interstitial form. Left ventricular ejection fraction can be assessed using echocardiography and rarely ventricular biopsy may be needed. Cardiac magnetic resonance imaging is a useful emerging non-invasive alternative to biopsy for the diagnosis of myocarditis. Glucocorticoids are the preferred treatment. Immunosuppressive therapies such as azathioprine and cyclophosphamide can be used in patients who do not respond to GCs. Use of anti-TNF agents is controversial as they can increase mortality when used in patients with severe heart failure [33, 34].

\section{Congestive heart failure}

There is an increased incidence of congestive heart failure (CHF) in RA patients when compared to the general population. Inflammatory stimuli seem to play an important role in the development of $\mathrm{CHF}$ in patients with RA [8]. Medications used in RA such as anti-TNF agents, NSAIDs and prolonged use of high-dose GCs can contribute to CHF. Diagnosis and management of CHF in RA is similar to that in those without RA.

\section{Cardiomyopathy and pericardial effusion}

People with RA at a higher risk of developing pericardial effusions compared to controls (odds ratio: 10.7;
95\% Cl: 5.0-23.0) [35]. Although pericardial effusion is a frequent cardiac complication of RA, in most cases it is mild and asymptomatic. Furthermore, left ventricular systolic myocardial function is found to be reduced in active rheumatoid disease [36], and the increased incidence of congestive heart failure in patients with RA compared to controls is a major contributor to mortality, separate to that of ischemic heart disease. Animal models confirm the long-term effects of rheumatoid arthritis on molecular remodeling and contractile function of the heart [37].

\section{Myocardial infarction}

Several studies have shown an increased risk of myocardial infarction (MI). Based on meta-analysis data, the standardized mortality ratio for fatal myocardial infarction is around 1.77 (95\% confidence interval $1.65-1.89)$, and the incidence rate ratio is $2.10(95 \% \mathrm{Cl}$ : 1.52-2.89) [38]. Patients with RA are also more likely to suffer unrecognized cardiac ischemic events.

Furthermore, patients with RA are at increased risk of $\mathrm{Ml}$ after major surgical procedures for up to 3 months [39]. A study by Mantel et al. [40] showed that patients with RA who have acute coronary syndromes (ACS) have increased short-term mortality with 7-day HR: 1.44, 95\% Cl: 1.14-1.82; 30-day HR: $1.36,95 \% \mathrm{Cl}: 1.13-1.64$ when compared to the general population who have ACS.

\section{Arrhythmias}

There is increasing evidence that arrhythmias are also more frequently seen in patients with RA. In a recent meta-analysis of three studies, the pooled risk ratio of development of atrial fibrillation in patients with RA versus controls was 1.29 (95\% Cl: 1.05-10.59) [41]. Even after adjusting for myocardial infarction, patients with RA are at twofold higher risk of sudden cardiac death when compared to the general population. There is also evidence of QT interval abnormalities and cardiovascular autonomic nervous system dysfunction being observed in patients with RA more frequently than in the general population. The exact mechanism is not yet known; animal models seem to point to atrial arrhythmogenic remodeling [42].

\section{Valvular thickening and nodules}

The presence of chronic inflammation in patients with RA increases the risk of valvular nodules to more than ten times compared to the general population. Valvular thickening is associated with a four-fold increased risk, and other valvular pathologies (stenosis, insufficiency, or prolapse) are also more prevalent in patients with RA [35]. 


\section{Stroke}

Ischemic strokes are the result of atherosclerosis, and it follows that patients with RA will be at increased risk. This is supported by the results of several meta-analysis studies, which report an incidence rate ratio of 1.91 and standardized mortality ratio (for fatal strokes) from 1.08 to 2.00 [38], and odds ratios of 1.64 to 1.68 [43]. This risk is significantly higher in young adults $(<50)$ with RA [43]. Also, RA increases the recurrence risk of ischemic strokes up to $47 \%$ and transient ischemic attacks up to $41 \%$, independently of other factors [44].

\section{Lymphatic obstruction}

A quite rare complication of RA is a lymphatic obstruction. There are very few cases described in the literature, some in juvenile RA [45]. The pathophysiology can be complex, relating to chronic inflammation, muscular inactivity, or the side effects of drugs.

\section{Peripheral vascular disease}

Peripheral vascular disease (PVD) is more prevalent in RA patients than in the general population. A study of non-smoking subjects comparing 234 patients with RA and 102 controls showed that peripheral arterial abnormalities (an abnormal ankle-brachial index and/or evidence of occlusion of a peripheral artery) were higher in RA patients (19\%) than in controls (5\%) [46]. In a retrospective study of 609 patients, the incidence of PVD was significantly greater in those with severe extra-articular features of RA than in those without these features (HR: 2.29, 95\% Cl: 1.20-4.34) [47]. Patients with RA appear to have up to 2 times higher occurrence of venous thromboembolism [27].

\section{Other cardiac complications}

One of the rare manifestations of systemic RA associated amyloid $A$ amyloidosis is cardiac amyloidosis. The gold standard for diagnosis is a myocardial biopsy, but it is invasive, so other newer modalities such as cardiac magnetic resonance imaging are being increasingly used. Prognosis is usually poor due to associated heart failure. Cytotoxic drugs and DMARDs can temporarily improve cardiac function, but progressive organ failure occurs despite aggressive treatment [48].

Non-infectious or autoimmune endocarditis is a rare but severe complication of RA. It can result in embolic disease or valvular dysfunction and may need valve repair or replacement. Myocardial ischemia can also occur in RA patients secondary to vasculitis, in addition to atherosclerotic disease [49].

\section{Prevention \\ Risk estimation}

Cardiovascular risk estimation is complex due to the different factors involved. To reduce complexity in clinical practice, several risk estimation tools that can calculate total CVD risk for the general population have evolved. One such tool is the SCORE, which estimates the 10-year risk of fatal CVD [50]. Others include the Framingham score, the QRISK1 and QRISK2, and the PROCAM, all of which also calculate the 10-year risk of CVD events [51].

With the exception of QRISK2, none of the other tools take into account the presence of RA, and they underestimate CV risk in this population [51]. Since rheumatoid arthritis enhances cardiovascular risk independently of other factors, it is recommended that a 1.5 multiplication factor be used in patients with RA [1].

Also, because the risk is dependent on disease activity, it is recommended that CVD risk assessment be undertaken every five years and also after major changes in anti-rheumatic treatment [1].

There are also efforts to predict risk based on other indicators. Endothelial function, as measured by flow-mediated dilation, has been found to be an independent predictor for future cardiovascular events, and there are early indications that measurements of endothelial dysfunction via the brachial artery method can be used as early predictors in patients with RA [52].

\section{General prevention measures}

Since the risk of CVD is higher in the presence of RA, it is advisable to be more diligent in prevention. Since there is not enough evidence to produce robust guidelines specific to patients with RA, it is recommended to follow national guidelines in CVD risk management with the use of antihypertensive and statins as in the general population [1]. Angiotensin-converting enzyme inhibitors and angiotensin receptor blockers are associated with decreased incidence of $\mathrm{Ml}$ in hypertensive patients with RA, possibly due to both anti-inflammatory and antihypertensive action [53].

A meta-analysis on the use of statins in patients with RA indicated that they may have an anti-inflammatory effect as well as a lipid-lowering property [54, 55], with atorvastatin reducing the disease activity score more than simvastatin, although there are conflicting reports where statins are associated with increased risk of developing RA in the first year of use [56]. Taking into account that some specific RA medications also affect the lipid profile of patients, it is advocated that lipid screening should be performed on all patients with RA as soon as they have achieved low disease activity $[2,57]$. 
Smoking is linked not only to CVD risk, but also to RA disease progression and reduced efficacy of the medication [58].

Exercise is also beneficial for patients with RA, and there is a planned randomized control trial that will examine the feasibility and effect of exercise provided as part of a cardiac rehabilitation program in patients with RA [59]. Unfortunately, feasibility studies on behavioral changes, including diet and exercise, highlight inherent challenges with regard to recruitment and drop out [60]. As such, the clinical applicability may be limited.

\section{Implications for rheumatoid arthritis therapeutic drug selection on cardiovascular risk}

It is clear that managing CV risk in patients with RA is complex. It is recommended that, in order to reduce CVD risk, antirheumatic-drugs should aim for optimum control of disease activity [1], GCs should be kept to the minimum [1], and NSAIDs should be given with the same caution as when prescribed in the general population [1].

\section{Conclusions}

The increase in the prevalence of cardiovascular diseases in patients with RA is multifactorial and a hot topic of research. Although there are still conflicting reports on the effect of the various anti-rheumatic drugs in CVD risk, it is generally recommended that the aim should be to reduce rheumatoid disease activity, because this appears to have a beneficial effect on cardiovascular risk. Until further research on whether patients with RA require more specific management of their $\mathrm{CV}$ risk is conducted, it is advocated to follow national guidelines as per the general population.

The author declares no conflict of interest.

\section{References}

1. Agca R, Heslinga SC, Rollefstad S, et al. EULAR recommendations for cardiovascular disease risk management in patients with rheumatoid arthritis and other forms of inflammatory joint disorders: 2015/2016 update. Ann Rheum Dis 2017; 76 17-28.

2. Roubille C, Richer V, Starnino T, et al. The effects of tumour necrosis factor inhibitors, methotrexate, non-steroidal antiinflammatory drugs and corticosteroids on cardiovascular events in rheumatoid arthritis, psoriasis and psoriatic arthritis: a systematic review and meta-analysis. Ann Rheum Dis 2015; 74: 480-489.

3. Tousoulis D, Oikonomou E, Economou EK, et al. Inflammatory cytokines in atherosclerosis: current therapeutic approaches. Eur Heart J 2016; 37: 1723-1732.
4. Rea IM, Gibson DS, McGilligan V, et al. Age and Age-Related Diseases: Role of Inflammation Triggers and Cytokines. Front Immunol 2018; 9: 586.

5. Hunt BJ, Jurd KM. Endothelial cell activation. BMJ 1998; 316: 1328-1329.

6. England BR, Thiele GM, Anderson DR, Mikuls TR. Increased cardiovascular risk in rheumatoid arthritis: mechanisms and implications. BMJ 2018; 361: k1036.

7. de Groot L, Hinkema H, Westra J, et al. Advanced glycation endproducts are increased in rheumatoid arthritis patients with controlled disease. Arthritis Res Ther 2011; 13: R205.

8. Gonzalez A, Kremers HM, Crowson CS, et al. Do cardiovascular risk factors confer the same risk for cardiovascular outcomes in rheumatoid arthritis patients as in non-rheumatoid arthritis patients? Ann Rheum Dis 2008; 67: 64-69.

9. Mattey DL, Thomson W, Ollier WER, et al. Association of DRB1 shared epitope genotypes with early mortality in rheumatoid arthritis: Results of eighteen years of followup from the early rheumatoid arthritis study. Arthritis Rheum 2007; 56: 14081416.

10. López-Mejías R, Castañeda S, González-Juanatey C, et al. Cardiovascular risk assessment in patients with rheumatoid arthritis: The relevance of clinical, genetic and serological markers. Autoimmun Rev 2016; 15: 1013-1030.

11. Navarro-Millán I, Yang S, DuVall SL, et al. Association of hyperlipidaemia, inflammation and serological status and coronary heart disease among patients with rheumatoid arthritis: data from the National Veterans Health Administration. Ann Rheum Dis 2016; 75: 341-347.

12. Baghdadi LR, Woodman RJ, Shanahan EM, Mangoni AA. The Impact of Traditional Cardiovascular Risk Factors on Cardiovascular Outcomes in Patients with Rheumatoid Arthritis: A Systematic Review and Meta-Analysis. PLoS One 2015; 10: e0117952.

13. Singh JA, Hossain A, Mudano AS, et al. Biologics or tofacitinib for people with rheumatoid arthritis naive to methotrexate: a systematic review and network meta-analysis. Cochrane Database Syst Rev 2017; 5: CD012657.

14. Arida A, Protogerou AD, Konstantonis G, et al. Atherosclerosis is not accelerated in rheumatoid arthritis of low activity or remission, regardless of antirheumatic treatment modalities. Rheumatology 2017; 56: 934-939.

15. Bally M, Dendukuri N, Rich B, et al. Risk of acute myocardial infarction with NSAIDs in real world use: bayesian meta-analysis of individual patient data. BMJ 2017; 357: j1909.

16. Dvirnik N, Belley-Cote EP, Hanif H, et al. Steroids in cardiac surgery: a systematic review and meta-analysis. $\mathrm{Br} J$ Anaesth 2018; 120: 657-667.

17. Rincón del I, Battafarano DF, Restrepo JF, et al. Glucocorticoid Dose Thresholds Associated With All-Cause and Cardiovascular Mortality in Rheumatoid Arthritis. Arthritis Rheumatol 2014; 66: 264-272.

18. Tam H-W, Yeo K-J, Leong P-Y, et al. Sulfasalazine might reduce risk of cardiovascular diseases in patients with ankylosing spondylitis: A nationwide population-based retrospective cohort study. Int J Rheum Dis 2017; 20: 363-370.

19. Vohra K, Krishan P, Varma S, Kalra HS. Exploring the potential of low-dose sulfasalazine in stable coronary artery disease pa- 
tients: randomized, double-blind, placebo-controlled study. Eur Heart J Cardiovasc Pharmacother 2015; 1: 214-216.

20. MacMullan PA, Madigan AM, Paul N, et al. Sulfasalazine and its metabolites inhibit platelet function in patients with inflammatory arthritis. Clin Rheumatol 2016; 35: 447-455.

21. Rempenault C, Combe B, Barnetche T, et al. Metabolic and cardiovascular benefits of hydroxychloroquine in patients with rheumatoid arthritis: a systematic review and meta-analysis. Ann Rheum Dis 2018; 77: 98-103.

22. Shapiro M, Levy Y. The association between hydroxychloroquine treatment and cardiovascular morbidity among rheumatoid arthritis patients. Oncotarget 2017; 9: 6615-6622.

23. Kisiel B, Kruszewski R, Juszkiewicz A, et al. Methotrexate, Cyclosporine A, and Biologics Protect against Atherosclerosis in Rheumatoid Arthritis. J Immunol Res 2015; 2015: 759610.

24. Lee JL, Sinnathurai P, Buchbinder R, et al. Biologics and cardiovascular events in inflammatory arthritis: a prospective national cohort study. Arthritis Res Ther 2018; 20: 171.

25. Low ASL, Symmons DPM, Lunt M, et al. Relationship between exposure to tumour necrosis factor inhibitor therapy and incidence and severity of myocardial infarction in patients with rheumatoid arthritis. Ann Rheum Dis 2017; 76: 654-660.

26.Xie F, Yun H, Levitan EB, et al. Tocilizumab and the risk for cardiovascular disease: a direct comparison among biologic disease-modifying antirheumatic drugs for rheumatoid arthritis patients. Arthritis Care Res (Hoboken) 2018. doi:10.1002/ acr.23737 [Epub ahead of print].

27. Kim SC, Solomon DH, Rogers J, et al. Cardiovascular Safety of Tocilizumab Versus Tumor Necrosis Factor Inhibitors in $\mathrm{Pa}$ tients With Rheumatoid Arthritis: A Multi-Database Cohort Study. Arthritis Rheumatol 2017; 69: 1154-1164.

28. de Souza Fatel EC, Rosa FT, Simão ANC, Dichi I. Adipokines in rheumatoid arthritis. Adv Rheumatol 2018; 58: 25.

29. Kawalec P, Śladowska K, Malinowska-Lipień I, et al. European perspective on the management of rheumatoid arthritis: clinical utility of tofacitinib. Ther Clin Risk Manag 2017; 14: 15-29.

30. Wu JJ, Strober BE, Hansen PR, et al. Effects of tofacitinib on cardiovascular risk factors and cardiovascular outcomes based on phase III and long-term extension data in patients with plaque psoriasis. J Am Acad Dermatol 2016; 75: 897-905.

31. Hurd ER. Extraarticular manifestations of rheumatoid arthritis. Semin Arthritis Rheum 1979; 8: 151-176.

32. Edwards MH, Leak AM. Pericardial effusions on anti-TNF therapy for rheumatoid arthritis - a drug side effect or uncontrolled systemic disease? Rheumatology 2008; 48: 316-317.

33. Mankad R, Ball CA, Myasoedova E, Matteson EL. Non-atherosclerotic Cardiac Manifestations of Rheumatoid Arthritis. In Handbook of Cardiovascular Disease Management in Rheumatoid Arthritis, Semb AG (eds). Adis, Cham 2017: 19-38.

34. Singh JA, Saag KG, Bridges SL, et al. 2015 American College of Rheumatology Guideline for the Treatment of Rheumatoid Arthritis: ACR RA Treatment Recommendations. Arthritis Care Res (Hoboken) 2016; 68: 1-25.

35. Corrao S, Messina S, Pistone G, et al. Heart involvement in Rheumatoid Arthritis: Systematic review and meta-analysis. Int J Cardiol 2013; 167: 2031-2038.

36. Midtb $\varnothing$ H, Semb AG, Matre K, et al. Disease activity is associated with reduced left ventricular systolic myocardial function in patients with rheumatoid arthritis. Ann Rheum Dis 2017; 76: 371-376.

37. Pironti G, Bersellini-Farinotti A, Agalave NM, et al. Cardiomyopathy, oxidative stress and impaired contractility in a rheumatoid arthritis mouse model. Heart 2018; 104: 2026-2034.

38. Meune C, Touzé E, Trinquart L, Allanore Y. High risk of clinical cardiovascular events in rheumatoid arthritis: Levels of associations of myocardial infarction and stroke through a systematic review and meta-analysis. Arch Cardiovasc Dis 2010; 103: 253-261.

39. Burn E, Edwards CJ, Murray DW, et al. The impact of rheumatoid arthritis on the risk of adverse events following joint replacement: a real-world cohort study. Clin Epidemiol 2018; 10 : 697-704.

40. Mantel $\ddot{A}$, Holmqvist $M$, Jernberg T, et al. Rheumatoid arthritis is associated with a more severe presentation of acute coronary syndrome and worse short-term outcome. Eur Heart J 2015; 36: 3413-3422.

41. Ungprasert P, Srivali N, Kittanamongkolchai W. Risk of incident atrial fibrillation in patients with rheumatoid arthritis: a systematic review and meta-analysis. Int J Rheum Dis 2017; 20: 434-441.

42. Dai H, Wang X, Yin S, et al. Atrial Fibrillation Promotion in a Rat Model of Rheumatoid Arthritis. J Am Heart Assoc 2017; 6: e007320.

43. Wiseman SJ, Ralston SH, Wardlaw JM. Cerebrovascular Disease in Rheumatic Diseases: A Systematic Review and Meta-Analysis. Stroke 2016; 47: 943-950.

44. Chen Y-R, Hsieh F-I, Lien L-M, et al. Rheumatoid arthritis significantly increased recurrence risk after ischemic stroke/transient ischemic attack. J Neurol 2018; 265: 1810-1818.

45. Schmit P, Prieur A-M, Brunelle F. Juvenile rheumatoid arthritis and lymphoedema: lymphangiographic aspects. Pediatr Radiol 1999; 29: 364-366.

46. del Rincón I, Haas RW, Pogosian S, Escalante A. Lower limb arterial incompressibility and obstruction in rheumatoid arthritis. Ann Rheum Dis 2005; 64: 425-432.

47. Liang KP, Liang KV, Matteson EL, et al. Incidence of noncardiac vascular disease in rheumatoid arthritis and relationship to extraarticular disease manifestations. Arthritis Rheum 2006; 54: 642-648.

48. Nakamura T. Amyloid A amyloidosis secondary to rheumatoid arthritis: pathophysiology and treatments. Clin Exp Rheumatol 2011; 29: 850-857.

49. Mason JC, Libby P. Cardiovascular disease in patients with chronic inflammation: mechanisms underlying premature cardiovascular events in rheumatologic conditions. Eur Heart J 2015; 36: 482-489.

50. Piepoli MF, Hoes AW, Agewall S, et al. 2016 European Guidelines on cardiovascular disease prevention in clinical practice. Eur Heart J 2016; 37: 2315-2381.

51. Hippisley-Cox J, Coupland C, Vinogradova Y, et al. Predicting cardiovascular risk in England and Wales: prospective derivation and validation of QRISK2. BMJ 2008; 336: 1475-1482.

52. Adawi M, Watad A, Bragazzi NL, et al. Endothelial function in rheumatoid arthritis. QJM 2018; 1-5.

53. Lin T-T, Wu C-K, Liao M-T, et al. Primary prevention of myocardial infarction with angiotensin-converting enzyme inhibitors 
and angiotensin receptor blockers in hypertensive patients with rheumatoid arthritis - A nationwide cohort study. PLoS One 2017; 12: e0188720.

54. Li G, Zhao J, Li B, et al. The anti-inflammatory effects of statins on patients with rheumatoid arthritis: A systemic review and meta-analysis of 15 randomized controlled trials. Autoimmun Rev 2018; 17: 215-225.

55. Soulaidopoulos S, Nikiphorou E, Dimitroulas T, Kitas GD. The Role of Statins in Disease Modification and Cardiovascular Risk in Rheumatoid Arthritis. Front Med (Lausanne) 2018; 5: 24.

56. de Jong HJ, Cohen Tervaert JW, Lalmohamed A, et al. Pattern of risks of rheumatoid arthritis among patients using statins: A cohort study with the clinical practice research datalink. PLoS One 2018; 13: e0193297.

57. Navarro-Millán I, Goyal P, Safford MM. Lipid screening and statins alongside disease-modifying anti-rheumatic drugs for patients with rheumatoid arthritis. Rheumatology (Oxford) 2018. doi: 10.1093/rheumatology/key302 [Epub ahead of print]. 58. Chodara AM, Wattiaux A, Bartels CM. Managing cardiovascular disease risk in rheumatoid arthritis: clinical updates and three strategic approaches. Curr Rheumatol Rep 2017; 19: 16.

59. Heinze-Milne S, Bakowsky V, Giacomantonio N, Grandy SA. Effects of a 12-week cardiovascular rehabilitation programme on systemic inflammation and traditional coronary artery disease risk factors in patients with rheumatoid arthritis (CARDIA trial): a randomised controlled trial. BMJ Open 2017; 7: e018540.

60. Garner S, Fenton T, Martin L, et al. Personalized diet and exercise recommendations in early rheumatoid arthritis: A feasibility trial. Musculoskeletal Care 2018; 16: 167-172. 